\title{
Boons and Bounds of Enterprise Resource Planning among SMEs in Sri Lanka
}

\author{
Pretheeba Pratheesh ${ }^{\mathrm{a}}$, Nidyanandan Pratheesh ${ }^{\mathrm{b}}$ \\ ap.pretheeba@gmail.com, ${ }^{\mathrm{b}}$ pratheesh_n@hotmail.com \\ Eastern University, Sri Lanka
}

\begin{abstract}
The present competitive business milieu enforced the organizations to implement effective measures which consecutively improve their capability towards competitive advantage. Enterprise Resource Planning (ERP) system is one of the widespread integrated advanced technology employed in many business organizations to gain and maintain competitive advantage. This system turn into famous in international as well as in local context. In Sri Lankan context Small Medium Enterprises (SMEs) are urged to implement ERP system however, the information on usage and benefits/issues arising from ERP usage especially in accounting performance is limited. Therefore this study was carried out with the aims of identifying the key benefits/issues faced by SMEs, the current level of ERP usage and the benefits and challenges during the implementation of ERP in selected SMEs in Sri Lanka. The research adopted a descriptive design employing standardized questionnaires as the primary data collection tool. The collected data were analysed through descriptive statistics minimum, maximum mean, and standard deviation in the findings. The analyzed data were presented using graph and tables. All this was accomplished via Statistical Package for Social Science (SPSS V 20). The study found that there is a average level of ERP usage among the selected SMEs in Sri Lanka also it is expected to have more improvement for the investment made.
\end{abstract}

Key Words: Enterprise Resource Planning; Competitive Advantage; Small Medium Enterprises; Benefits; Challenges

\section{Introduction}

The present dynamic business environment force the organizations under pressure to improve the profitability and productivity via the performance. Focus on business strategy is one technique employed by organizations to increase profitability and performance on the other hand exploit new technology which support to increase the productivity. In the current business milieu most of the enterprises adopt new technology to attain efficiency and effectiveness which bring down the production's unit component cost. The enterprise resource planning one among the many integrative technology that has recognized by many firms to enhance both the efficiency and the effectiveness.

Enterprise resource planning (ERP) is the general expression applied in management software which comprise different modules such as accounting, finance, logistics, stock control, marketing and human resources which allow firms to prepare for their products or services (Stevenson, 2007). The ERP system integrated management information from internal and external management environment of the organization, supporting for finance/accounting, manufacturing, sales and service, customer relationship management, etc., (Hossein, 2004).

Normally the ERP was implemented by larger enterprises. However at present the adoption of ERP is not limited to larger enterprises. The usage of ERP system among the small- and medium-sized enterprises (SMEs) is instigated to increase (Loh and Koh, 2004). ERP systems was adopted by several organization in less well developed economies to settledown some of their manufacturing management issues. The number of studies available in this area is inadequate and the studies available reveals that (Ioannou and Papadoyiannis, 2004; Spathis and Constantinides, 2003; Towers et al., 2005) ERP systems adopted and implemented get diverged when compared with some companies in developed economies specially UK and US.

In addition, the ERP system has received significant attention from academic researches focused mostly on the motivations for ERP implementations and the factors contributing to the success and failure of ERP projects and the ERP benefits obtained from implementing the system. Implementation of ERP system is not a simple process. The organization or the user needs to check it beside numerous success/failure factors to ensure effective execution, as well as to avoid execution dangers. ERP system was successfully implemented by many organizations, whereas some others abandon in implementation of ERP projects or fail to achieve their envisioned result. A preliminary information collected among few SMEs in Sri Lanka observed that still the SMEs are not IJRP 2020, 55(1), 25-29; doi:10.47119/IJRP100551620201263 
actualize ERP systems due to the drawbacks of subscription fees, cost of updates, high maintenance cost, need for redesign the business process, need for new trained employees, customization and integration limitations, security and performance risks etc., however there are few SMEs adopt the ERP system. Hence this exploratory research focuses on adoption level of ERP systems among Sri Lankan SMEs especially for accounting activities and its impact on performance of the firms in order to promote SMEs about the usage of the ERP system.

\section{Methodology}

Self- administered questionnaire and interview were used in data collection process from the respondents. Population was given the examining nature of the research, few small medium enterprises that have implemented ERP systems were targeted within a definitive limit,

The researcher used primary sources of data. The sample for the study was thirty-six (36) respondents from nineteen (19) selected SMEs in Sri Lanka. Convenient sampling technique was adopted as a non-probability sampling technique. This sampling technique is where a sample (subjects) is selected based on the researcher's convenience like availability of the subjects. The research instrument used in this study comprised close ended likert scale question that was adopted from Spathis and Constantinides (2004). The administration of the questionnaire helped the researchers to have a good rapport and also help to explain the purpose of the study to the respondents. Questionnaire divided in to five parts, such as the first part discourses general information considering the type of the company and the type of the business which the SMEs is belongs, followed by the personal information of the employees who are working under the accounting department, accounting methods and modules operate in the ERP environment, reasons for the implementation of ERP systems and the issues that companies have encountered when working with the ERP systems. In the identified SMEs 07 SMEs adopt the ERP system and 11 SMEs does not adopt ERP technology. 15 respondents belongs to ERP adopting SMEs whereas 21 respondents belongs to non-ERP SMEs.

\section{Data Presentation and Analysis}

The collected data were mainly analysed using descriptive tools and statistics, such as bar charts, pie charts, mean and standard deviations and presented in tabular and graphical format. Accountnts of the ERP system adopted companies recorded that they are using number of modules in the ERP environment. They are operating almost 50\% of the modules identified such as financial accounting, management accounting, costing, production, e-commerce and payroll modules. Furthermore they are using the other modules also to ease the accounting process. It was summerized in the table -1 below.

Table 1: Modules Operate in ERP Environment

\begin{tabular}{lll}
\hline & Number & Percentage \\
\hline Financial Accounting & 15 & 100 \\
Management Accounting & 15 & 100 \\
Costing & 15 & 100 \\
Production & 15 & 100 \\
E-Commerce & 15 & 100 \\
Payroll & 15 & 100 \\
Fixed Asset Register & 12 & 80 \\
Stock purchase & 12 & 80 \\
Quality Management & 08 & 53 \\
Logistics & 07 & 53 \\
\hline
\end{tabular}

It is evidenced form the results that even though Sri Lanka as a developing country the SMEs in Sri Lanka have more interested in integrating the new system in to their accounting activities, which could make ease of their accounting practices. The respondents of the study also asked why they have interest towards use of ERP. They stated that the ERP system help them to amalgamate the flow of information in the real time. It facilitate them to integrate the financial system of the organization with other core business activities such as production, quality 
control, inventory, procurement, etc.,. Further the reason for adopting the ERP system in given in the following chart.

\subsection{Reasons for Adoption of ERP systems}

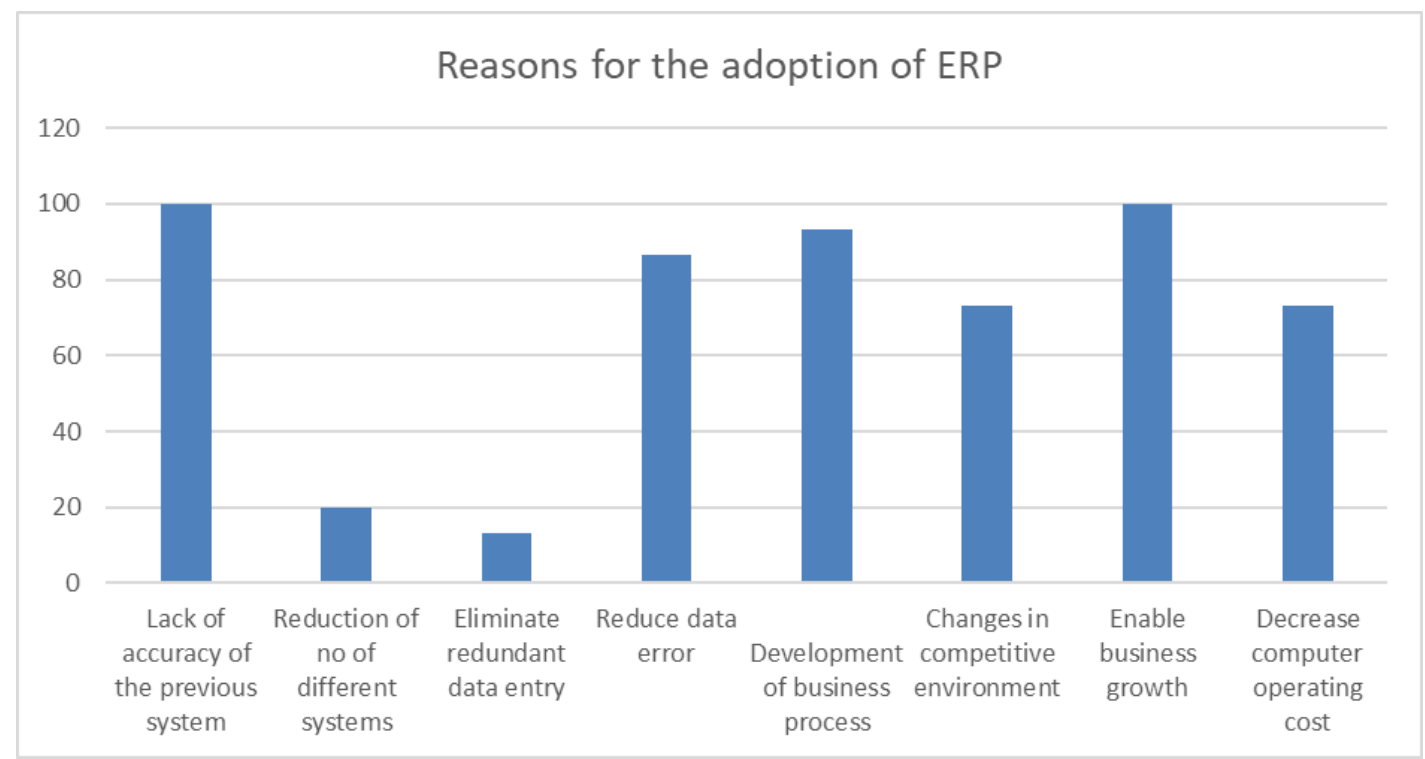

Fig. 1. Reasons for the adoption of ERP

Figure 1 reveals the reasons the SMEs are paying attention in employing the ERP systems. The responses shows that they are willing to adopt ERP system since it intensify the accuracy and also reduces the data errors which ultimately support for the development of business process and business growth. In few SMEs, the accountants experience the use of ERP system reduce the usage of different systems and reduce unwanted data entry. However still there are some enterprises that do not adopt ERP system. The figure 2 reveals the reasons behind not adopt or implement ERP system within the organization.

\subsection{Reasons behind the not implementation of ERP systems}

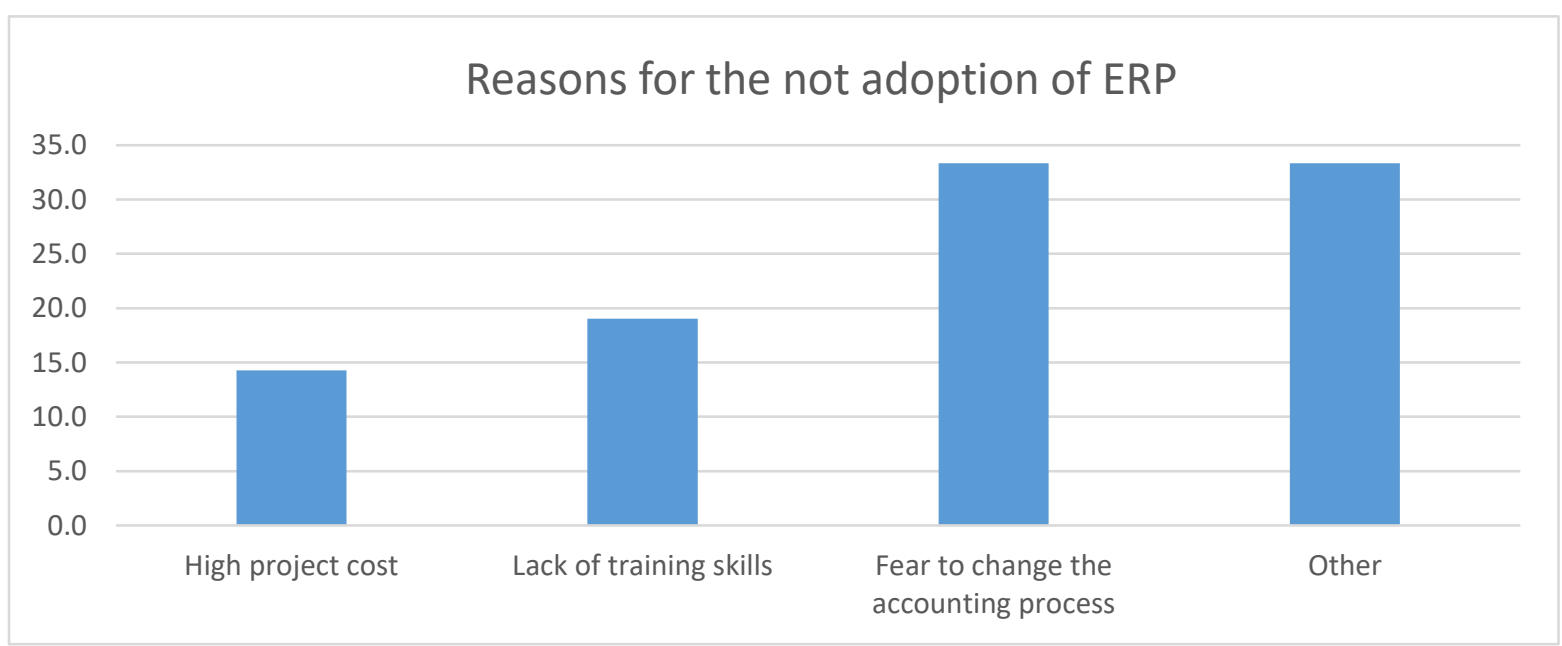

Fig. 2. Reasons for the not adoption of ERP

As mentioned above chart it represent reasons for the SMEs are not tend to implement the ERP systems. As a results collected through questionnaire, main reason is fear to change the accounting process with the new technology as a percentage $33 \%$. Other category indicates such as management non-willingness to adopt the ERP, customization difficulties, fear to change the scope of project implementation and difficulties faces when combining the organizational goals with the ERP system. 
Table 2: Descriptive statistics for benefits of ERP System

\begin{tabular}{lll}
\hline Benefits & Mean & SD \\
\hline Reduction of time for closure of monthly accounts & 3.46 & 1.22 \\
\hline Reduction of time for closure of quarterly account & 3.67 & 1.42 \\
\hline Reduction of time for closure of annual accounts & 3.53 & 1.27 \\
\hline Reduction of time for transaction processing & 3.73 & 1.21 \\
\hline Reduction of time for issuing of reports statements of accounts & 4.33 & 1.60 \\
\hline Improved quality of reports - statement s of accounts & 3.20 & 0.76 \\
\hline Improved decision making process & 3.86 & 1.27 \\
\hline Improved internal audit function & 3.40 & 1.42 \\
\hline Improved working capital control & 4.13 & 1.47 \\
\hline Increased use of financial ratio analysis & 3.33 & 1.09 \\
\hline Reduction of time for issuing payroll & 3.80 & 1.24 \\
\hline Reduction of personnel accounting department & 3.53 & 1.22 \\
\hline Increased flexibility in information generation & 3.33 & 1.09 \\
\hline Increased integration of accounting application & 4.15 & 1.33 \\
\hline
\end{tabular}

Source: Survey Data

The respondents were encouraged to mark the actual benefits perceived and realized by them via the introduction of ERP systems on a six-point likert scale in turn to assess the real effect of ERP system. The most highly rated perceived benefits achieved via ERP systems relate to "Reduction of time for issuing of reports on statements of accounts", "increased integration of accounting applications" and "improved working capital control". The development of technological features in ERP systems allow firms to provide facilities to reduce of time for issuing of reports and enhance the quality of decision making. Also, ERP systems grant users to get quality reports where more user friendly and understandable and also has supported to reduce the time of processing reports with the integration between departments and more technical features.

Further benefits such as reduction in time for closing monthly accounts, use of new tools and techniques, reduction in transaction processing time, ease of accountant's job and activities and increased integration of other operational functions with accounting process have been rated with high rates with justifying the fact that ERP provides more effective business solutions compared to conventional accounting systems.

Furthermore it was identified some other advantages also achieved through the system to a considerable level such as "improving understanding and knowledge of accountants", "improved quality of decision making", "improved decisions based on timely and reliable information". Further, "Increased use of financial ratio analysis", "Improved working capital control ", "Improved internal audit function" have also been quoted. However the above stated benefits are achieved to some extent by the organization still they need to pay more attention to get resilient advantage out of their investment. During the implementation of ERP system the selected organizations face the following problems.

\subsection{Problems faced during and after the ERP implementation}

Table 3: Descriptive statistics for Challenges of ERP System

\begin{tabular}{lccccc}
\hline & $\mathrm{N}$ & Minimum & Maximum & Mean & Std. Deviation \\
\hline External security attacks & 15 & 3.00 & 5.00 & 3.6667 & .61721 \\
Conflicts with consultants & 15 & 2.00 & 5.00 & 3.6000 & .82122 \\
$\begin{array}{l}\text { Conflicts with employee } \\
\text { resistance }\end{array}$ & 15 & 3.00 & 5.00 & 4.0667 & .70373 \\
$\begin{array}{l}\text { Conflicts with business } \\
\text { strategy }\end{array}$ & 15 & 3.00 & 5.00 & 4.2000 & .77460 \\
\begin{tabular}{l} 
Project cost \\
\hline
\end{tabular} & 15 & 3.00 & 5.00 & 3.7333 & .70373 \\
\hline
\end{tabular}


Table 3 portrays the challenges while operating the ERP systems. The findings reveals that the highest mean 4.2 is for the conflicts with business strategy. It means that companies have a multi year business plans and targets to achieve. The adoption of ERP create conflicts with plans, actions and key measurements. This is not only the case for SMEs mostly in all the business setting who have implement ERP systems, have faced this issue at the early phase. Therefore, this is considered as the high-ranking downside during the implementation of ERP systems. Another drawback is conflicts with employee resistance with the mean value of 4.06. Because the introduction of new technology and procedures will bring transformations to the way people work in the organization and it may tend to reduce the number of employees and reorganising the responsibilities among the employees, this may evoke internal conflicts between the new skilled employees and long-standing employees. And also the project cost scored somewhat high mean value of 3.73, which indicates that the development and implementation of ERP within an organization environment. ERP software project cost isn't inexpensive. It incorporates cost for modules, consultant charges, hardware, training, maintenance and upgrading, etc., other than this firms have the fear of cyber criminals attack and the conflicts with the consultant which shows the mean value of 3.66 and 3.60 respectively.

\section{Conclusion and Recommendations}

Based on the collected information it was identified that there are number of benefits the SMEs enjoyed via the implementation of ERP system even though the system is accompanied with few challenges as conflicts with business strategy, employee resistance, high project investment, external security attacks and conflicts with consultants. However, the benefits derived from the implementation of ERP system outweigh the challenges exist.

\section{References}

Loh, T.C., Koh, S.C.L. 2004. Critical elements for a successful ERP implementation in SMEs, International Journal of Production Research 42, p. 3433-55.

Ioannou, G., Papadoyiannis, C. 2004. Theory of constraints-based methodology for effective ERP implementations, International Journal of Production Research 42, p. 4927-54.

Spathis, C.. Constantinides, S. 2004. Enterprise Resource planning Systems Impact on Accounting Process, Business Process Management Journal 10 (2), p. 234-247

Spathis, C., Constantinides, S. 2003. The usefulness of ERP systems for effective management, Industrial Management \& Data Systems 103, p. 677-85.

Towers, N., Knibbs, A., Panagiotopoulos, N. 2005. Implementing manufacturing resource planning in a Greek aerospace company: a case study, International Journal of Operations \& Production Management 25, p. 277 89. 